\title{
Audio and Video Media in Teacher Training: Deterritorialization in Education
}

\author{
Dante Augusto Couto Barone1, Milton Antonio Zaro², Cláudio de Musacchio², \\ Andrea Moraes ${ }^{3}$, Arisnaldo Adriano da Cunha ${ }^{4}$ \\ ${ }^{1}$ Program Post Graduate Institute of Informatics, UFRGS, Porto Alegre, Brazil \\ ${ }^{2}$ Graduate Program of Computers in Education, UFRGS, Porto Alegre, Brazil \\ ${ }^{3}$ E.T.E. Vieira de Mello School, Esteio, Brazil \\ ${ }^{4}$ Graduate Program of in Education, UFSC, Florianópolis, Brazil \\ Email: barone@inf.ufrgs.br, zaro@ufrgs.br, claudiodemusacchio@gmail.com, \\ andrea.moraes97@yahoo.com.br, arisnaldoadriano@yahoo.com.br
}

Received 3 November 2015; accepted 23 May 2016; published 26 May 2016

Copyright (C) 2016 by authors and Scientific Research Publishing Inc.

This work is licensed under the Creative Commons Attribution International License (CC BY).

http://creativecommons.org/licenses/by/4.0/

c) (i)

\section{Abstract}

This study aimed to study the influences of the pedagogical use of audio and video media by students in the production of educational content, using Internet research, reflections on the information and the recording of audio and video by secondary school students themselves in a public school in Rio Grande do Sul. The main question sought to answer how to use multisemiotic literacies of reading, writing, pictures, photos, audio and video production of school content to obtain meaningful learning. Preliminary results indicate a gradual increase in motivation and reflection of students by research, reading and writing the information in the teaching of the Portuguese language and literature. The experience has also shown the need for teacher training for the pedagogical use of communication, interaction and collaboration environments in social networks and technical training in the use of audio and video media in the classroom. The positive points observed in the research are the improvement of the capacity for reflection, motivation for contextual research, use of social networks as a communication and collaboration environment in group work, production of educational materials in audio and video media, improved self-criticism due to physical exposure of the students in the videos, speaking in public and $360^{\circ}$ assessment performed by the students.

\section{Keywords}

Interdisciplinarity, Interdisciplinary Teaching Methods, Audio and Video Media in Education, Deterritorialization in Education, Social Networking in Education 


\section{Introduction}

Interdisciplinary teaching practices are part of a big picture of educational social movements, which increasingly seeking more discussion on the solutions to basic education, primary and secondary in Brazil. The aspects and features of this education that is required are the implications of a program that makes it possible to approximate the areas of disciplinary knowledge to interdisciplinary contours, allowing an education that strives for excellence in their practice as a learning that makes sense for the students.

The formation of education professionals has been the keynote of studies of researchers from all over the world and an interdisciplinary perspective, since it is in the daily lives of teachers and students, interdisciplinarity is in different multisemiotic literacies (reading, writing, pictures, photos, audio and video), and the school is sought to stabilize a system of theoretical and methodological propositions that can cope with the curriculum content through the prerogative that the areas of knowledge come together not only to establish themselves as processes of teaching, construction of syllabus and didactic regulations, but also as a classroom practices, with the presence of two or more teachers, in the same physical and subjective space of the subject, enabling a more active student participation and the opportunity of a universe changes arising from the sharp practice of collective thought.

To make this possible rapprochement between the fields of knowledge and to seek an epistemological apology to justify the different shades of educational practices in the management structures of formal education, courses are necessary to conceptualize some features of this education that seeks to investigate. As a first step, therefore, we start the concepts given in the meeting held at the University of Nice (France, 1970, entitled "First International Seminar on Multi, Pluri and Inter and Transdisciplinarity ${ }^{1 »)}$ ).

Thus, the term appears as "inter- and transdisciplinary", according to Jean Piaget, which shall "represent a new horizon of studies for the differential treatment of complex problems and attempt to overcome the limits of focused knowledge, uniquely, in unidisciplinary paradigm” (Philippi, 2011: p. 178).

According to Finance (2008), there is a conceptual redemption that should considered as relevant with respect to the practice of interdisciplinarity, when talking simplistically, the use would be reduced only to the integrator aspect of disciplines. According to observations of the author, the school, in contemporary times, he noticed a broader sense of its use also seeking to integrate other agents or actors of the relationship, as teachers and students, students and students, schools and families.

However, the question that always does, and it's motto of this research is that these processes are responsible to whom the success or failure of methodological and technological applications to teaching practices, so that interdisciplinary judge? Japiassú (1976) built the foundation for this understanding, along with his friends at the seminar, Erich Jantsch, Heckhausen, Boisot and Lichnerowicz. The extent to which technologies have important role in the success of methodologies, interdisciplinary or not, and end up promoting a deep dispossession in education at all levels?

In this article, we will show some initiatives, which do not respond, give the new inquiry hues player and in this sense understand how, with the aid of technology, Facebook social network environment, and the pedagogical use of audio and video media can significantly improve motivation, collaborative behavior, the written reflection and readings through different proposed literacies and therefore promote the construction of knowledge, based on the model "Learning to Do", the four pillars of fundamental learning, presented by Delors (1998), in a report to the International Commission on Education for the Twenty-First Century-UNESCO.

\section{Interdisciplinary Concepts}

\subsection{Interdisciplinary Teaching Practices}

Whereas the Interdisciplinary presents itself as a result of an epistemological necessity and a contemporary requirement, so that we can suggest relevant changes in education and in the form of construction of knowledge, thus implying changes in individual and institutional dimensions, we need to historically understand how given the evolution of educational processes and teaching practices (Fazenda, 2008).

As Santos (2002) points out, to understand the conceptual thinking of teaching practices must be used as Cartesian historical thought that forged the positivist thought, based on the formation of scientific thought derived

${ }^{1}$ At this meeting, as reported in Philippi (2011), occurred in February 1970, gathered 21 representatives from OECD member countries, integrating a group of experts present were Jean Piaget, Heinz Heckhausen, Eric Jantsch, Marcel Boisot, Georges Gusdorf Andre Lichnerowicz, Asa Briggs, Leo Apostel. 
from two formal subjects: logic and mathematics; and the empirical sciences, focused on the mechanistic model of the natural sciences.

Morin (1996) describes this issue in the following terms the question of interdisciplinarity as a motto to guide the pedagogical practices,

...Founded on rationalism and empiricism, the hegemonic paradigm of classical science, focuses on disciplines that ignore what exists between and beyond their borders. Is guided by a positivist and objectivist conception of science, with deterministic laws, timeless, operating from dichotomous categories, such as man and nature, science and humanities, objective and subjective, nature and culture, normal and abnormal, qualitative and quantitative [Morin (1996); Morin (2000, 2002b)].

As the thought of Kuhn $(1978,2002)$, the hegemonic paradigm of science said "normal” rule out other forms of knowledge construction than from the perspective of positivism. If considered variables such as hermeneutic or dialectical, so common in areas such as sociology, the theoretical and methodological perspectives that characterize the relationship between subject and object, in much differ from the classic positivism.

According Alvarenga et al. (2011) and Sommerman (2006), interdisciplinarity appears as a precursor in the search for answers to the limits of simplifying knowledge, dichotomous and discipline of modern science, becoming for many researchers and researchers, an innovative way scientific knowledge construction, while it is an alternative and complement to the traditional way of thinking discipline.

In his work "The Epistemology of interdisciplinary relations", Piaget (1972) states that there are three levels of relationships that arise between the disciplinary components, ranking as specific forms of knowledge, in addition to disciplinary model: multidisciplinary, interdisciplinarity and transdisciplinary.

Since the proposed Jantsch \& Bianchetti (2002) differs significantly from Piaget, to demonstrate that the phenomena of interdisciplinary and transdisciplinary occur between the sciences the prerogatives of education and innovation, enabling the educational system's ability to renew itself, an increasing spiral. It adds that in relation to limits for multi, multi and cross-disciplinary, it is only with

The interdisciplinary and transdisciplinary that the education system and innovation comes to life, in the sense that the content, structures and disciplines junction points are constantly changing under the influence of coordination links established to pursue the goal of a system with a. The interdisciplinary and transdisciplinary become thus key notions to undertake teaching and innovations in optical systems (Jantch, 2002: pp. 107-108).

Note that this article aims to propose a working strategy that uses interdisciplinarity as a factor adding to the pedagogical practices of teachers. Therefore, it is necessary to establish a methodology that addresses the interdisciplinary use associated with these methodologies that emphasize interdisciplinary spaces and technologies to appropriate mechanisms that provide potential conditions of excellence in teaching and learning quality.

\subsection{Deterritorialization in Education}

The word deterritorialization in the dictionary means to lose territory. However, a more cartographic analysis, its meaning can be seen as a change in subjectivity of the subject to the object. According Ianni (1992) (Ianni, 1996, 1999) “...The subject of knowledge does not stay in one place, letting its gaze float through many places, near and remote, in present and past tenses, real and imagined." In this sense, gives a sense of stability and organization, action deterritorializing is proposing disorder, in order to get another proposal of perception, another reflection or revision of previously existing reflections, is introducing new aspects and characteristics that established in the territory.

Guattari \& Rolnik (1996) contributes saying territory is synonymous with appropriation of subjectivity closed in on itself, and that being a set of representations that end a series of stereotypical behaviors, dogmatic and perpetuated for centuries. What is proposed in this field of research is the discussion of this location and spatial pragmatic existing between teacher and pupil, between TEACHING and LEARNING and between teaching and learning.

The dispossession concept is Gilles Deleuze (2002), in the field of Geography, and here in this study greatly helps to promote new spaces for discussion and studies in Education, Pedagogy and Cognitive Psychology, promoting an interdisciplinary model that gave rise to studies of the original proposal the Neuroeducation. 
The proposed deterritorializing of education by changing the dialogue promoted by the terrain of the relationship between teacher and student, does it propose that there is a repossession elsewhere in analysis of educational methodologies. If new roles in the Teacher and Student territories are possible, it will also be possible to include new variables to the model proposed and thus observe the phenomena through new lenses and filters on the behaviors and expressions of teachers and students facing the challenges of the search for better education.

\subsection{Concept of Delocalization and Spatialization of the Classroom}

Communications between the territory TEACHER and STUDENT are still considered by many international theorists as a relationship of power, so that the spaces at the school require students likely to listen more than talk, and teachers opting more for the lecture in the expense of so many other possible ways to get the attention and the necessary student motivation for learning in search of excellence.

It is assumed, therefore, that what is sought is to analyze the possibility of a different relationship between the actors capable of producing a dispossession and ceasing to exist in one way or another: teacher to student. It is considered important in this concept that communication and education are side by side, formalizing two different directions, one to the other, no longer having the figure of the transmitter or the receiver's figure and, yes, of Peirce dialectical exchanges, where the two, teacher and student, and can exercise the same rights of communication: talking and listening. In this sense, it gives a relocation of the sense of subjectivity that classroom space exerted on the actors and now promotes new dimensions.

In Geography, Cresswell (2004) in his book "Place: a short introduction" cites the political geographer Agnew (1987), who cites, in a classical and didactic way, three fundamental aspects to the understanding of place: location, locale and sense of place.

Location represents the fixed and objective coordinates of a point on Earth. The word place is often used as a sense of location. But as Cresswell (2004) explains, places are not always fixed, only its coordinates. For example, a ship on high seas, is currently somewhere, even if this location is constantly changing. When traveling by car through a small town, you can mention that you are somewhere and then a moment later, somewhere else. Now, the concept of locale refers to things, objects. For example in a city, the location is comprised within the material extension about the references used.

Another commonly used concept of place is the association, which Cresswell (2004) describes, of places that may even no longer exist, except in our minds and memories. It is on this concept of subjective place that the reflection of this research is worked on. Delocalization, used in this context, is attributed to the change in positioning in regards to opinion, argument or expression on what a place was like, but is no more due to a physical change of transposition and subjective sense.

The study of DELOCALIZATION in education therefore has the sense to link subjectively, how the educational scenario in traditional education once was and how it is being proposed by the new methods of teaching and learning.

The relocation and classroom spatial distribution is a phenomenon that occurs more and more in scenarios of new interdisciplinary teaching practices, and the social networking environment falls on school places with new subjectivity of hues, offering students and adolescents to motivation want to study, learn, interact and collaborate with each other. In addition to the innovative aspect of the exposure to the tasks to build the content themselves, through audio and video, networks provide new relations in the construction of subjectivity itself, as subjects that are, and how they see themselves in production the school subjects, which now do not favor both multisemiotic literacies writing and reading but also of representations of languages such as pictures, photos, audio and video.

\subsection{Multisemiotic Literacies and Production of School Subjects}

Since Mark Presky notable named "digital natives”, for the generations that were born with the digital language, that is, with access to computers, mobile tablets, Internet and social networks, significantly improved the understanding of how the technologies fit into the lives of individuals. According Presky (2001), all other generations are called "digital immigrants", who despite not being born in the digital world period, have adopted practices and uses of technologies.

According to Tapscott (2010), the children began to use other literacies that not only reading and writing and developed cognitive skills with the different languages of representation. 
In a way,

"Technology is influencing the way children think and behave, but it is a two-way hand-the way children think and behave is influencing and shaping the Internet itself. In the twenty-first century, knowledge is flowing more freely than ever thanks to the Internet, but the true potential of the Internet was only achieved when young people began using computers. Now they are helping to transform it into something new-the Internet 2.0, live internet, Hipernet, active Internet. Name it-this is not your father's Internet. She has become a global computer, active, networked, which allows everyone to not only participate but also to change its nature" (Tapscott, 2010: p. 69).

With the use of different forms of representation, children begin to better understand your space with this company as a network of social interaction and communication practices, with intensive collaboration. According to Schneider (2007), the cyberspace culture allows children to become interplanetary, globalized by the media and not only understanding your backyard space, but the backyard of many children from other countries, cultures and distant peoples. Dornelles (2005) defines this childhood as a Cyber childhood, a global childhood, scaled by global information productions spaces and understandings of the different forms of literacies. Children start to adopt not only a culture, a dialect or a pattern of thinking about things and worldview.

According to Veen \& Vrakking (2009), the homo denomination zapping It is defined by the result of this connection of children with the digital world at all scales from access by changing the way of researching, producing information and relate to others.

Dornelles (2012) draws attention to the approach of teaching practices that must be inserted into the twenty-first century teacher when he says that,

...To deal thus with what some theorists call postmodern childhood and cannot help questioning about the effect of some cultural artifacts that are part of children's culture as: Internet, design, 3D movies, magazines, toys, etc., in children's lives. As you need awaken in children a certain criticality of these devices in order to enable them to understand how these are produced, disseminated and consumed and how they can, thereafter offering new significance in (Dornelles, 2012: p. 83).

But why multisemiotic literacies are so important in education? It is necessary to distinguish the difference between literacy and literacy, for composing the concepts of technological literacy and literacies multisemiotic culminating in innovative and creative teaching practices.

Tfouni $(1995,2000,2002)$ defines literacy as the resource that focuses on the historical social aspects of purchasing a system written by a company, unlike the concept of literacy, which deals with the acquisition of writing by an individual or group of individuals.

To Warschauer (2006a; 2006b; 2006c), other types of literacies arise with IT and the Internet, so considering the electronic literacy, reporting that demand nurtured with the spread of computers and the Internet, changed the social fabric requiring other skills and qualifications teachers to digital literacies, including figures, photos, audio and video are configured innovations in teaching and learning. The audio and video media literacies are increasingly demanded by contemporary pedagogical practices, requiring methodological and technological innovation teachers.

FACEBOOK environment has six multisemiotic literacies and is a place where the culture of digital natives is already widespread in society. However there is much to be done to train teachers and educational institutions managers to the mode of production of educational content, using these environments as technological support for the creation of meaning. In this sense, the research presented in this article has experienced these technologies with students and preliminary findings may shed light on the understanding of new demands by the practice and teaching faculty. Considering the dispossession caused by new features and respects the roles of teachers and students across the pedagogical use of such technologies, the construction of subjectivities is possible by the subjects through the educational use of technologies and methodologies that favor such innovative features (Musacchio, 2011a, 2011b).

\subsection{Web Radio in Education}

In this perspective the production of educational content, is established as a guiding principle and the ability of the student's ability to conduct research by computer, more specifically, with the help of Internet. According to Moraes (2008), the last 20 years, changing the center of gravity of international capital, which previously rested 
on the big centers and communication and global information, now find themselves displaced to the media of social networks and diverse information production. The population is empowered Information System, making it forming of opinion and exerting major role in the acquisition, exchange and decision-making. Thus, the TV and radio, occupying key highlights during the last decades, are now incorporating new news production processes, audios and videos. It is estimated that at least $70 \%$ of the world population that access the Internet are regularly producing some kind of information and influences circulating in networks.

In education, as the same site radios in 2004 were only 114 educational initiatives across the country, and in early 2015, now total over 2300 units in elementary schools, middle and upper. Radio web applications in education are varied. According to Moreira (2002), the greatest motivation still remains the music, however, is already being added also, increasingly, news and educational information to students, teachers and families of students, integrating the school to parents and community in a way general.

According Kunh (2002), there are countless radio web application advantages in education: the web radio sound can be heard on any modern device, just that this device has Internet access; information have different structures such as text, graphics, photos, audio and video; building virtual communities to interact with the radio synchronously or asynchronously; recording programs and availability of programs in specific sites of the web radios; ability to intervene in the programming of web radio by listener interactivity to answer questions on specific forms on the sites; surveys, polls, auctions, online interviews, testimonials, live or on-demand transmissions, and many other attractions make the web radios the most revolutionary means of communication today.

Recording lessons can be heard at different times by students, interviewing visitors at school can be reviewed in the extensive web radio programming. In this article we describe the pedagogical use of web radio through the exhibition of student work from audios and videos made in the classroom.

\section{Interdisciplinary Research Achievement}

For this research some indicators to watch were created, both qualitative and quantitatively, the interactions carried out in the classroom and in the proposed virtual environments. It was adopted four main groups of observation of the production of students: interdisciplinary encounters, scientific and educational research, production of audio and video and posts Productions on FACEBOOK, through the groups created for this purpose.

Table 1 presents the indicators found during the research.

Interdisciplinary meetings: Interdisciplinary encounters can be understood as actions undertaken in the classroom with the contribution of two or more teachers, discussing and reflecting on the issues that are common to different areas of knowledge. In this research, these meetings allowed the discussion of topics previously chosen by teachers and students to research and reflect on the problems of the discussed phenomena.

Scientific and academic research: A suggestion for activities involving scientific research in the classroom, with students divided into small groups, made it possible to analyze the relationships established with the educational use of technologies such as social networks and video and audio in the production of the results of the proposed activities. The technologies used were researches in search engines on the Internet, books in the library and interviews with teachers of the areas of the subjects researched.

Sound and video: It was suggested that students build audios and videos about the considerations made in documents raised. The audios were used for the interviews and the videos for the production of research. The methodology comprises the script learning (storyboard) and recording of audio and video by the groups themselves. The videos had different textual, theatrical and musical, content presented in the formats of television news, dramatization, parodies, in the form of conversation between the elements of the groups and testimonials from students regarding the subject researched.

Posts: Students use the environment FACEBOOK study group for the posting of the researched information.

Table 1. Activities proposed to the groups surveyed.

\begin{tabular}{|c|c|c|c|c|c|c|}
\hline ACTIVITIES & GROUP A & GROUP B & GROUP C & GROUP D & GROUP E & TOTAL \\
\hline INTERDISCIPLINARY MEETINGS & 3 & 3 & 3 & 3 & 3 & 15 \\
\hline SCIENTIFIC AND SCHOOL RESEARCH & 31 & 18 & 27 & 12 & 6 & 94 \\
\hline AUDIO AND VIDEO PRODUCTION & 40 & 19 & 17 & 18 & 6 & 100 \\
\hline POSTS ON FACEBOOK & 172 & 114 & 87 & 32 & 16 & 421 \\
\hline
\end{tabular}

SOURCE: Author. 
Each teacher received a resource from the FACEBOOK study group to serve as communication, interaction and collaboration among students during the research. The posts are presented in multisemiotic literacies: text, graphics, photos, audio and video.

The activities were offered to students in two modes: and virtual. Grouped by up to five participants, each group was responsible in researching a particular subject content. The students could conduct research on search engine sites on the Internet and in libraries and in-person or virtual. It was also requested that the information found to be made up of text, photos and figures on the subject researched. To compose the information activity in multimedia environment, we asked students to record audio of the interviews conducted during the period as well, periodic videos of the meetings of the students to advance research. So there would be systematic monitoring of the whole process (Tables 2-4).

The amount of interactions carried out according to the indicators used in the survey showed the following results.

Initially, teacher training was carried out with the WEB RADIO IN EDUCATION and FACEBOOK IN EDUCATION courses, giving rise to the application of the concepts necessary so that the research could be performed. Public schools were chosen randomly in cities surrounding Universidade Federal do Rio Grande do Sul. The cities surveyed were: Porto Alegre, Esteio, Sapucaia do Sul, Canoas e Viamão.

Table 2. Groups surveyed and analyzed from March to June 2015.

\begin{tabular}{cccc}
\hline STUDY GROUPS & $\begin{array}{c}\text { EDUCATIONAL } \\
\text { INSTITUTIONS }\end{array}$ & $\begin{array}{c}\text { NUMBER OF } \\
\text { STUDENTS }\end{array}$ & $\begin{array}{c}\text { NUMBER OF } \\
\text { TEACHERS }\end{array}$ \\
\hline PRIMARY SCHOOL GROUP A & 2 & 86 & 2 \\
SECONDARY SCHOOL GROUP B and C & 2 & 210 & 2 \\
UNDERGRADUATE STUDIES GROUP D & 1 & 80 & 1 \\
TECHNICAL LEVEL PROGRAMS GROUP E & 1 & 22 & 4 \\
\hline
\end{tabular}

SOURCE: Author.

Table 3. Assumptions and results-aspects and features.

\begin{tabular}{lc}
\hline \multicolumn{1}{c}{ FIELD RESEARCH IN NUMBERS } & TOTAL \\
\hline 1) Interdisciplinary meetings (two or more teachers in the classroom), 15 interdisciplinary meetings in the groups studied \\
2) Use of FACEBOOK in the classroom (Study Groups), 6 FACEBOOK Study Groups for each study group \\
3) Use of Audio and Video media in the classroom, 398 students participated in the survey \\
4) Students set in groups in the classroom, 97 groups of students (four-five participants) \\
5) Suggestion for the production of content by the students themselves, 100 school contents studied \\
6) Scientific and school researches held in the classroom, 94 school researches \\
7) Use of the FACEBOOK environment by teachers and students, 407 student and teacher profile accounts \\
8) Creation of FACEBOOK STUDY GROUPS, 17 study groups \\
9) Periodic posts on FACEBOOK of group activities, 421 posts on FACEBOOK \\
10) Likes and Shares by students to their personal profiles, 1819 likes and shares \\
11) Interdisciplinarity with teachers from other areas of knowledge, 124 interviews with teachers and area experts \\
11) $360^{\circ}$ assessment of students (everyone evaluates all posts), 12 tests performed during the research \\
12) Learning of audio and video editors Format factory and Movie Maker, 512 productions of intermediate and final videos \\
13) Use of Movie Maker for editing of videos by students, 185 videos with credits about the surveyed subjects \\
14) Production of scientific articles and publishing of activities by teachers, 8 scientific articles published in specialized \\
magazines and newspapers \\
15) Technical specifications of the activities performed by invited institutions, 4 technical notebooks on the activities \\
16) Vocational Training and Qualification for Teachers, WEB RADIO IN EDUCATION and FACEBOOK IN THE \\
CLASSROOM
\end{tabular}

SOURCE: Author. 
Table 4. Links to FACEBOOK study groups used in the research.

\begin{tabular}{ccc}
\hline STUDY GROUPS & LINK & MEMBERS \\
\hline WEB RADIO IN EDUCATION & https://www.facebook.com/groups/webradio.na.educacao/ & 4334 \\
EDUCATIONAL RESEARCHES & $\underline{\text { https://www.facebook.com/groups/pesquisas.escolares/ }}$ & $\mathbf{4 0 2 6}$ \\
\hline
\end{tabular}

SOURCE: Author.

\section{Indicators for Research}

Table 5 shows the indicators used to observe the characteristics of the educational model proposed in the research and verify the deterritorialization of the TEACHER AND STUDENT fields, seeking to enter new existing aspects and characteristics through assignments to the actors of education. The analysis of the experiences that occurred during the study was grouped into the characteristics described in the table above, and then exposed to the observations of the researcher:

Educational research - The indicator of scientific research in the classroom was used so that students could propose their hypothesis and proving them or refute them, by checking the data over the Internet and by search engines for information.

Activities group - This indicator made it possible to verify the performance of students in group activities and how would relations concerning communications, interactions and collaborations. Students could use the study group on FACEBOOK to relate, exchange ideas, take questions and may add to the classroom researched information.

Media audio and video - The activities carried out in students' groups were stored in audio and video. It was requested for a research to be conducted and for the information to be worked in the format of a script and recorded in videos. Students and teachers were trained to use the FORMAT FACTORY, free program, which must be installed on the user's computer, and that allows you to change the file type, given that the kind used in mobile or machine recording, do not work properly with the types allowed in the MOVIE MAKER basically considering the most common: MP3 and MPEG.

Steps supervised-This indicator has shown how the study groups have organized to accomplish the tasks. What functions was made by each member of the group? What technologies and methodologies used to build the research required? As stored information? In what ways and how the data was stored? These questions were added to the research information and steps were videotaped and posted on YOUTUBE own members of each group.

Document construction-The construction documents is an indicator created so that it could analyze how students would conduct research and how they would organize the documents from the research. Should organize text, graphics, photos, or even audio and video, in addition to interviews conducted as part of the collected documents.

Reflections and roles assumed-This indicator were prioritized reflections that students should realize that they might produce audio and video related to the researched documents. The challenge was for the students to be able to read the information researched and build a reflection on the subject, with the purpose of recording videos.

Individual contributions - This indicator investigated how each student participated in the group activity for collecting the information, comprised of texts, graphics or photos. This way we would know exactly what each one had researched, reflected and produced to make up the whole of the research.

Global view of activities-This indicator write down the contents of the respect the group's dialogues of the information acquired and how they have organized to participate in the final video. OVERVIEW OF ACTIVITIES-Students were asked to perform recordings of the discussions between them on the subjects researched as well as talk about the interviews conducted with teachers from other areas, thus providing the interdisciplinary required with other areas of knowledge.

Assessment of performances-This indicator noted the impressions of students across the audio and video technologies, related to various behaviors in front of the microphone and cameras. ASSESSMENT OF PERFORMANCES — with the purpose of recording the videos, students should watch the participations of all work carried out.

Group assessment-The groups of students surveyed were asked to conduct an assessment of each 
Table 5. Deterritorialization in education.

\begin{tabular}{|c|c|c|}
\hline \multicolumn{3}{|c|}{ INDICATORS OF DETERRITORIALIZATION IN EDUCATION } \\
\hline MAIN CHARACTERISTICS & $\begin{array}{l}\text { METHODOLOGY EMPLOYED } \\
\text { INTERDISCIPINAR }\end{array}$ & $\begin{array}{l}\text { TECHNOLOGIES EMPLOYED IN } \\
\text { FIELD RESEARCH }\end{array}$ \\
\hline $\begin{array}{l}\text { SCIENTIFIC AND SCHOOL } \\
\text { RESEARCHES }\end{array}$ & World understanding through experimentation & $\begin{array}{l}\text { Research in search engines and ABNT } \\
\text { writing of technical texts }\end{array}$ \\
\hline ACTIVITIES & $\begin{array}{c}\text { Working in communication, interaction and } \\
\text { collaboration }\end{array}$ & $\begin{array}{c}\text { Use of synchronous communication } \\
\text { systems }\end{array}$ \\
\hline STAGES OF RESEARCH & Encouraging collaborative reflection & Use of FACEBOOK and HANGOUT \\
\hline CONSTRUCTION OF DOCUMENTS & $\begin{array}{c}\begin{array}{c}\text { Production of school subjects by the students } \\
\text { themselves }\end{array}\end{array}$ & Building documents collaboratively \\
\hline PLAN OF CONTENT & Construction of audio and video storyboards & $\begin{array}{l}\text { FORMAT FACTORY AND MOVIE } \\
\text { MAKER Software }\end{array}$ \\
\hline $\begin{array}{l}\text { AUDIO AND VIDEO MEDIA IN THE } \\
\text { CONSTRUCTION OF CONTENT }\end{array}$ & $\begin{array}{l}\text { Multisemiotic content: reading, writing, pictures, } \\
\text { photos, audio and video }\end{array}$ & $\begin{array}{c}\text { FACEBOOK environment and other social } \\
\text { networks }\end{array}$ \\
\hline $\begin{array}{l}\text { REFLECTIONS } \\
\text { OF CONTENT }\end{array}$ & $\begin{array}{c}\text { Interpretation of texts and production of } \\
\text { dialogues }\end{array}$ & $\begin{array}{c}\text { Audio and Video of interviews and } \\
\text { dialogues }\end{array}$ \\
\hline INDIVIDUAL PARTICIPATIONS & Everyone is seen and heard by everyone & Recording of individual participations \\
\hline OVERVIEW OF ACTIVITIES & Activities of the groups are seen by all students & FACEBOOK Platform Study Groups \\
\hline $\begin{array}{l}\text { ASSESSMENT OF } \\
\text { PERFORMANCES }\end{array}$ & $\begin{array}{l}\text { Watch the videos of colleagues and their } \\
\text { reflections }\end{array}$ & Recording interviews of participants \\
\hline $\begin{array}{c}\text { GROUP } \\
\text { ASSESSMENT }\end{array}$ & Learning how to judge the participations & $\begin{array}{l}\text { Use of FACEBOOK Platform Study } \\
\text { Groups }\end{array}$ \\
\hline $\begin{array}{l}\text { ASSESSMENT BY } \\
\text { STUDENTS- } 360^{\circ}\end{array}$ & Everyone evaluate everyone & $\begin{array}{l}\text { Assessment through posts on the } \\
\text { FACEBOOK environment }\end{array}$ \\
\hline $\begin{array}{l}\text { PUBLICATION ON THE } \\
\text { SOCIAL ENVIROMENT }\end{array}$ & $\begin{array}{l}\text { Collective and individual production of school } \\
\text { subjects }\end{array}$ & Publication in YOUTUBE web pages \\
\hline $\begin{array}{l}\text { CONSTRUCTION OF } \\
\text { THE E-SOCIAL }\end{array}$ & $\begin{array}{c}\text { Construction of the students' image in social } \\
\text { networks }\end{array}$ & Social networking in education \\
\hline
\end{tabular}

SOURCE: Author.

member of the group. For this, they would have to watch the videos of classmates and reflect on the participation of each. In this regard, students would be studying the participation of classmates and building the idea of thorough research.

Assessment 360 - The assessment of the indicator entitled 360 comprises the observation of the students towards the activities that each played during the survey conducted in the classroom. The evaluation criteria encompassed information production questions, script of the videos and effective participation in the images.

Publication in social media-Each participant should create a YouTube channel to publish their participation in the activities. In addition, they should also place links of the videos on the FACEBOOK Study Group Environment.

E-social construction-Students were invited to create profiles on the social network to learn how to live with the use of image in an increasingly mediatic world. Generations X and Y are known by the use of mobile devices and the ease of use of audio and video in society.

\section{Observations on the Indicators and Results}

According to the indicators used in the survey, the results were quite promising, if we judge the acceptance rate the methodological proposal to build oriented teaching practices for interdisciplinary, the educational use of social networking in education, especially the FACEBOOK platform and use audio and video media in the construction of the contents performed by the students in the studied subjects.

Next, the indicators and key topics relevant to the implementation of the methodology proposed in schools:

Educational research-The results of the search activity, organization and preparation of the information in 
textual means showed no novelty compared to traditional education systems, it was already known to the group analyzed. However, by including innovation multisemiotic literacies, that is, entering figures and photos and recording audio and video, there has been considerable change in the behavior of groups, from the dress, posture, presentation, speech, image exposure, increasing self-criticism of their holdings.

Activities group-According to statements of the surveyed students and teachers themselves, any attempt to put students into groups to work Afterschool became a frustrating activity, marked by a number of reasons, and already set in previous studies dissertations of master's and doctoral theses.

Audio and video media - For this indicator the students were asked to record audio and video for the proposed activity. Students and teachers were trained to use the FORMAT FACTORY software, which allows you to change the file type to the types accepted by MOVIE MAKER, to be used for editing and placement of credits. The results of using these technologies had almost no technological innovation by the students, since the generation Z, (12 to 19), already had experience in producing these files.

Steps supervised - The spread of methodological approach is the monitoring of the proposition made during the research papers and media exposure of what the groups are doing, the way to get the information and what they are thinking about it. The indicator's strategy is to capture information about the proposed activity, as the groups are organized, who are the leaders, they distribute tasks, how each element behaves in front of their own participation in the group.

Document construction-This indicator shows the results through multimedia presentation, differing from the traditional model of presentation of schoolwork. Instead of organizing the information in a text, putting paragraphs, figures, tables and charts or the subject researched, students should submit the final document in a multimedia textual presentation, and is composed of text, pictures, photos, audio and video.

Reflections and roles assumed - This indicator investigated the extent to which students had improved proposition to reflect on investigating and what opinion they would have on the subject. In the work in school generally, attention is always focused on the end product is a written document and handed a sheet of paper.

Individual contributions - The challenge of the modern education system of schools is to have each student can, in time and with the degree of difficulty or understanding, express themselves on what is understood in the classroom, the activity being presented. With concern primarily focused on content, have to complete in a timely manner all information from the syllabus, teachers often "run" with the contents without giving a chance for students to reflect on such matters.

Global view of activities-This indicator, the methodology presented innovative and creative results, as surveyed reported never having been experiences where they could discuss, watch and comment on all the work done in the classroom. Generally, say the students, activities are carried out and subsequently handed over to the teacher. "Who reads all jobs are teachers, who learn about all the subjects covered are teachers" said one of the students.

Assessment of performances-Self-criticism is not a traditional pedagogical activity in the education system. Students are not accustomed to seeing in multimedia environments and do the necessary self-criticism of their behavior, facial expressions, gestures and posture in the face of physical exposure.

Group review - This indicator pointed the assessment needed for the teacher to know, by the traditional criteria of evaluation, it was learning and she was level. In the traditional system of education, students typically perform tests containing questions of all kinds, in a way that student learning is observed.

Assessment 360 - This indicator was investigated as students conducted to evaluate 360, i.e., an evaluation in which all the participation of all evaluated during the search. It was suggested that students attend all audios and videos produced in the survey and made available on YOUTUBE.

Publication in social media-This indicator examined the publications of productions made in the activities. According to the students, post "for the world school activities was a fascinating experience" Causing strange to some, and many joys to others. In the testimonies of the students one can see the importance of using the global process of learning.

E-social construction-This indicator was observed how students felt using the Facebook platform to build network of social relations. The proposed construction of the social network is because the students already participate in this tool out of school and therefore already have contact with many people far away from your everyday life. 


\section{Results of Research and Learning}

As results obtained through data collection instruments and formal evaluation (questionnaires and interviews), the indicators showed patterns of behavior in the classroom and the methodology used in the experiment (a total of 398 reviews and nine interviews with teachers).

During the formal assessment, through evidence, which can be seen was a marked improvement in the final notes of the participating classes. Through the survey questionnaires, one can gather information on the model applied and how these activities affect the daily lives of students in the classroom.

The interdisciplinary aspect, characterized piece action of two or more teachers in the classroom, represented a radical change because the contents were collaborated by different disciplines, giving students greater dialogic understanding of knowledge areas. Only $2 \%$ of teachers had knowledge of the interdisciplinary methodology and how it is processed in the classroom. And 78\% of teachers said they were not seeking information with other teachers on the topics covered in class, seeking themselves the information when needed.

The difficulty of teachers in interdisciplinary actions involving more than one discipline at the same time in the classroom is due to the operational difficulty of teachers are at school during the hours of other disciplines. In this research, this difficulty was circumvented by using the same time teachers to join the class and discuss issues in common.

Figure 1 shows the result of interdisciplinary methodological application provided substantial improvement on tests. According to the students themselves, this was due to study the activities by placing students in the role of scientific research of the subjects covered in the preparation of the researched information and assembly of scripts for recording videos.

In the communication aspect, social networks accounted decisive role in empowering and enabling students to a communication system between them that could put them in constant contact. This communication proved relevant for students to exchange more information, taking your questions and thinking more about the issues.

Regarding the behavioral aspect and image display, the result was more pronounced than in other indicators. The exposure of students to videos and audios, built a new relationship with the students themselves. When they saw in the videos, were able to make a self-criticism about their subjects, their interpretation, voice, tone, form of expression and so were able to develop improvements in reflection, in the construction of ideas, arguments and opinion formation about the issues, improving including discourses and speeches.

In the methodological aspect, interdisciplinarity brought new life to the teachers by providing favorable environment for the exchange of knowledge in different disciplines in the classroom by placing students at the center of discussions and allowing them greater understanding of the defined borders of each area of expertise (discipline) to understand the phenomena studied.

Of all the indicators studied, representing major result was the one who put the teacher in an apprentice position, that is, gave them the opportunity they can, along with the students, seeking the answers of the subjects

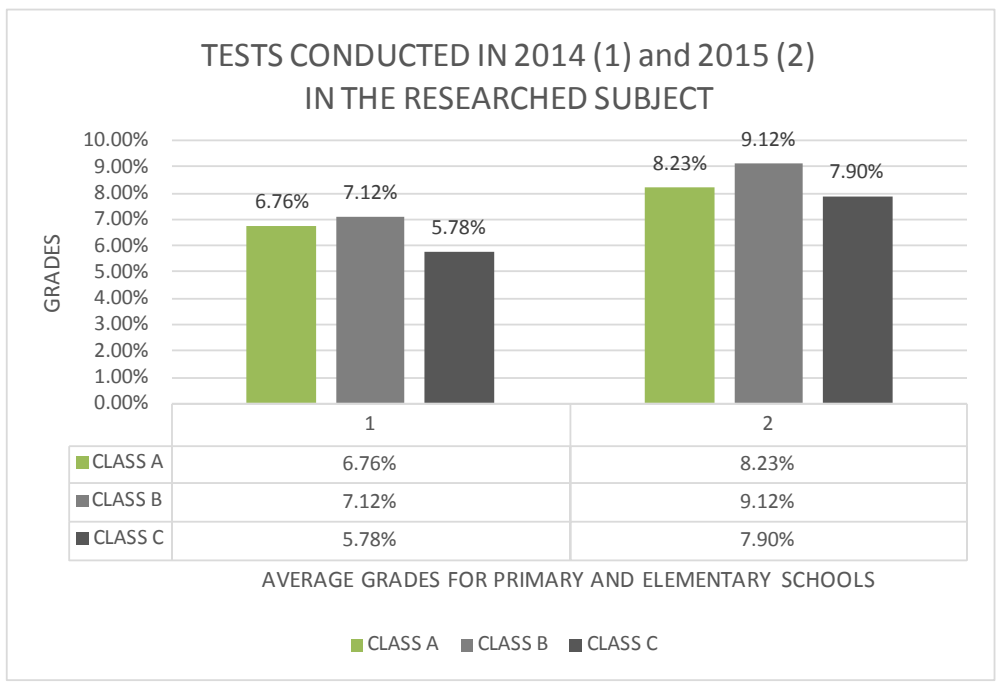

Figure 1. Results achieved in tests (SOURCE: Author). 
studied and learned from them. To this must be a feature of the social network that puts all participants as a NODE, which receives and gives information where everyone ask questions and somehow respond to the rest of the group. The empowerment of social networks in the classroom gives opportunity to everyone to have time and voice, because everything is recorded.

\section{Final Considerations}

Search results, even in preliminary dimensions, may indicate advances in interdisciplinary teaching practices in teaching and techniques of pedagogical use of media, allowing to take on new roles and characteristics of the deterritorialization in education, placing the different epistemological knowledge more united in the construction of educational programs. The paradigm of two or more teachers in the classroom has been tried in the classroom for teachers and students demonstrated an improved understanding of the different aspects that every matter may contain when approaching the border sciences disciplines.

Also, how the use of social networking opportunities provides improvements in the quality of communication, interactions and collaborations of students to produce scientific and/or academic research is explained. Also the use of different multisemiotic literacies (pictures, photos, audio and video), in addition to reading and writing, which are widely used in the traditional teaching model, demonstrates that different representations of languages allow students to learn better, as some learn more through pictures and photographs instead of reading and writing, and some learn more through audio and video, improving the reflection than researches using only reading and writing for schoolwork.

In the research, we could also observe teachers and students more united by technological proposals for social networking in the classroom, with the aim of facilitating interactions and collaborations allowed in these virtual communication environments.

Information sharing during classroom projects in group work seemed to bring new life to the students who felt too lonely, compared to other study groups in the classroom. In general, this type of activity brings together four or five students in each group, but the groups do not have communication with each other, leaving a large gap to be worked by the teachers.

The exhibition of students in audio and video environments brought a new perspective to the design and subjective self-criticism, considered a challenge for applications using these technologies. The methodology to be implemented should take care of some important aspects on pain of falling into the same traditional model of teaching and learning. Innovation and creativity of the proposed methodology is precisely to propose that students produce audio and video for the task at hand, so there is management of teachers on the progress of tasks, as well as path-changing opportunities for the search for new information.

Another challenge that the school should quickly start the operation concerns the construction of the E-Social, i.e., that each student is oriented to the production of the network of relations geared to your area of expertise required. This challenge must begin at school after the $7^{\text {th }}$ grade of elementary school and guide until the last year of high school. Among the environments studied are FACEBOOK, mentioned in this research, Twitter, YOUTUBE, LinkedIn, and others.

Assessment systems should be rethought by managers of primary and secondary educational institutions so that teachers and students build models where not only the content is assessed, but also social behavior, facial, gestural and postural expressions, construction of audio and video media, and assessment are carried out by the student of the educational system, their participation in the media improves the self-criticism and self-image that students build by themselves.

Finally, this research can serve as a stimulus for other initiatives to study interdisciplinary methodologies and technologies, and how to improve teaching practices towards a teaching and learning excellence and significant results for an education whose duration endure well beyond the school day. The child and adolescent development and the construction of knowledge should have the same importance as the subjective growth of the subject and how it sees these social relations that the school provides opportunities. More studies should move in this direction, seeking to investigate new aspects and characteristics of teacher and student territories to enable the dispossession education that aims to improve teaching and learning.

\section{References}

Agnew, J. (1987). Place and Politics. The Geographical Mediation of State and Society. Boston: Allen Unwin. 
Alvarenga, A.T. et al. (2011). History, Philosophical and Theoretical-Methodological Fundamentals of Interdisciplinarity. In A. Philippi Jr. \& A. J. Silva Neto (Eds.), Interdisciplinarity in Science, Technology \& Innovation. Interdisciplinarity in Science, Technology \& Innovation (Vol. 1, pp. 3-68). Barueri: Manole.

Cresswell, T. (2004). Place: A Short Introduction. Oxford, UK: Wiley.

Delors, J. (Coord.) (1998). The Four Pillars of Education. In Cortezo (Ed.), Education: The Treasure within (pp. 89-102). São Paulo: Cortezo.

Fazenda, I. (org.) (2008). What Is Interdisciplinarity? São Paulo: Cortez.

Guattari, E., \& Rolnik, S. (1996). Micropolitics: Cartography of Desire. Petrópolis: Vozes.

Ianni, O. (1992). The Global Society. Rio de Janeiro: Civilização Brasileira.

Jantsch, A. P., \& Bianchetti, L. (Orgs.) (2002). Interdisciplinarity: Beyond the Subject of Philosophy. Petrópolis: Vozes.

Japiassú, H. (1976). Interdisciplinarity and Pathology of Knowledge. Rio de Janeiro: Imago.

Kuhn, T. (1978). The Structure of Scientific Revolutions. São Paulo: Perspectiva.

Kunh, F. (2002). The Radio on the Internet: Going towards the Fourth Media. VIII Symposium of Research in Communication of the Southeast Region, Vitória-ES, 10 January 2002.

Moraes, M. C. (2008). Ecosystemic Thinking: Education, Learning and Citizenship in the Twenty-First Century (2nd ed.). Petrópolis: Vozes.

Moreira, A. F. B. (2002). Curriculum, Cultural Difference and Dialogue. Education \& Society, 23, 15-38.

Morin, E. (1996). The Epistemological Problem of Complexity. Lisbon: Europe-America Publications.

Musacchio, C. (2011a). PSIU PROFESSOR-Scientific Research in the Classroom-Experimental Education (p. 176). Porto Alegre: Editora Alcance.

Musacchio, C. (2011b). TESTS-Interdisciplinarity and Scientific Research in the Classroom (p. 254). Porto Alegre: Editora Alcance.

Piaget, J. (1972). Genetic Epistemology. In H. F. Japiassu (Ed.), 1934. Introduction to the Epistemological Thought (p. 202). Rio de Janeiro: Francisco Alves, 1934

Philippi Jr., A., \& Silva Neto, A. (Eds.) (2011). Interdisciplinarity in Science, Technology \& Innovation (p. 997). Barueri: Editora Manole.

Santos, J. M. T. P. (2002). The Limit of Necessity: Interposed Conditionalities to the Performance of the Educational Work at School. In: N. S. C. Ferreira (Eds.), Educational Supervision for a Quality School: From Education to Action. São Paulo: Cortez.

Schneider, H. (2007). The Reporting Mobile: A New Platform for Citizen Media. In: K. Nyíri (Ed.), Mobile Studies: Paradigms and Perspectives (pp. 159-167). Vienna: Passagen Verlag.

Sommerman, A. (2006). Inter or Transdisciplinarity? From Disciplinary Fragmentation to a New Dialogue between Knowledges. São Paulo: Paulus.

Tapscott, D. (2010). The Time of the Digital Generation. Rio de Janeiro: Editora Agir.

Tfouni, L. V. (1995). Literacy and Wording. São Paulo: Cortez.

Tfouni, L. V. (2000). Terra Pátria. Porto Alegre: Editora Sulina.

Tfouni, L. V. (2002). My Demons. Rio de Janeiro: Bertrand Brazil.

Veen, W., \& Vrakking, B. (2009). Homo Zappiens: Educating in the Digital Age (p. 141). Trad. De Vinícius Figueira. Porto Alegre: Artmed.

Warschauer, M. (2006a). Technology and Social Inclusion: The Digital Exclusion Debate. São Paulo: Senac.

Warschauer, M. (2006b). Laptops and Literacy: Learning in the Wireless Classroom. New York: Teaches College Press.

Warschauer, M. (2006c). Learning the Digital Age. Educational Leadership, 63, 34-38. 